\title{
Adapting instruments and modifying statements: The confirmation method for the inventory and model for information sharing behavior using social media
}

\author{
Tiny Azleen Binti Yahaya ${ }^{a^{*}}$, Khairuddin Idris ${ }^{a}$, Turiman Suandia and Ismi Arif Ismaila
}

${ }^{a}$ Department of Professional Development and Continuing Education, Faculty of Educational Studies, Universiti Putra Malaysia, 43400, Serdang, Selangor, Malaysia

\begin{tabular}{l}
\hline C H R O N I C L E \\
\hline Article history: \\
Received: November 26, 2017 \\
Received in revised format: Janu- \\
ary 31, 2018 \\
Accepted: April 7, 2018 \\
Available online: \\
April 7, 2018 \\
\hline Keywords: \\
Information Sharing \\
Social Media \\
Exploratory Factor Analysis \\
Employee Behavior \\
Human Resource Management
\end{tabular}

\begin{abstract}
A B S T R A C T
This study aims to confirm the information sharing behavior using social media scale and to validate every item and make it reliable as an inventory by using Exploratory Factor Analysis (EFA). The researcher adapted the measuring instruments for every latent construct from the literature and customized the items to suit this particular study. The study sent the revised questionnaire to 262 respondents in order to gather the pilot study data and able to get 163 filled ones as final data. The set of questionnaires consists of 66 items that assess the 6 constructs. Data is analyzed using SPSS AMOS Version 21.0. The results show that every construct achieved its Bartletts' Test of Sphericity $<0.05$ and the measure of sampling adequacy by Kaiser-Meyer-Olkin (KMO) $>6.0$ with the result of Information Sharing Behavior .000 and .871; Intention .000 and .782; Belief Expectancy .000 and .911; Attitude Influence .000 and .925; Readiness For Change .000 and .959; and SelfEfficacy .000 and .902 . The entire item of the construct has exceeded the minimum limit of 0.7 reliability of Alpha Cronbach value to achieve the Internal Reliability. The new integrate model has been proposed due to this finding.
\end{abstract}

\section{Introduction}

Information sharing in the information, communication and technology era (also known as ICT for short) is not subject to face-to-face meetings, notice memos on the notice board, or printed circular anymore (Singh et al., 2018). The digital world has already begun to take over the forms of information sharing. Social media and various internet-based software, make the process of information sharing much easier. Web 2.0, where the idea has generated by Tim O'Reilly during a media conference in 2004 sees these social media software as a main priority in today's world. "Networks as platforms" mean that the importance of social media usage is more than just offering applications through its software network (service) but also becomes an application that benefits organizations, users, and network providers. Software such as Flickr, Snapfish for sharing photographs, Blogspot, Wordpress for sharing stories, Wikipedia for sharing factual information as well as Facebook, WhatsApp, MySpace, Twitter, LinkedIn for interactive sharing are some of the software offered in Web 2.0 technology. This medium has not only become the choice of individuals but also of international organizations. The finding of a 
study by one of the famous research University that is University of Massachusetts Dartmouth Centre for Marketing Research found that, as reported in Fortune500 magazine, all the top 10 companies used social media mediums as their main choice of information sharing activities with their users and clients. In 2014, Facebook showed the highest amount of usage by the organization and became the choice among companies in the Fortune500 list. In 2016, Instagram became one of the highest choice. The Malaysian Communications and Multimedia Commission (MCMC) reported that in 2015, statistics showed more than 20.1 million internet users in Malaysia and 16.8 million were actively using Web 2.0 social media software. Web 2.0 software offers a choice of online information sharing that is transparent, fast and interactive.

\subsection{Government Linked-Investment Company (GLIC)}

Through the researcher's review of a number of government linked investment companies (GLIC) in Malaysia, the researcher has found that all five GLIC companies in the special projects list under the purview of the Malaysian Prime Minister's Department have an official website and sosial media site. In fact, the Prime Minister, Deputy Prime Minister as well as the Cabinet have personal social media accounts and official ones like Facebook, Blog, Instagram, LinkedIn and websites. GLIC are now in the process of using social media to share the information of their services, among them, stocks status, company activities, product lists, services as well as advertising company products and services. Understanding that the development of the digital world and the phenomenon of social media usage is happening in the ICT world, in organisations and upon individuals worldwide including in Malaysia, this study determines a dependent variable, that is information sharing behavior using social media and identifies independent variable factors and constructs as predictor factors, mediator factors and moderator factors that are expected to have a significant relationship with information sharing behavior using social media. Through study and research, through borrowing, merging, adapting, sentence modification and translation via past research instruments, the researcher has produced a set of survey questions as an instrument to measure information sharing behavior using social media through a pilot study carried out on the employees of government linked investment companies (GLIC) confirming the suitability of this study to be carried out among the employees of other organisations.

\subsection{Model and instruments}

The research model and survey inventory of this study adapts models and instruments built by various earlier researchers. For the proposed model, this study refers to the main theory and model from Unified Theory of Acceptance and Use of Technologies (UTAUT) by Venkatesh et al. (2003), Theory of Reasoned Action by Fishbein and Ajzen (1975), Theory of Planned Behavior by Ajzen (1991), Expectancy Theory by Vroom (1964), Change Theory by Lewin (1946), Readiness for Change by Armenakis and Bedeian (1999) and Holt et al. (2007), Self Efficacy by Bandura (2001;1977), Intrinsic Extrinsic Motivation Theory by Ryan and Deci (2000) followed by various references of past studies. For the proposed instrument of this study, the researcher took, adapted and modified a number of statements from past reference sources in order to ensure compatibility with the field of study being carried out. Since this study remodels a new set of instruments by taking, adapting as well as modifying and translating items from instruments of past research, therefore, the researcher has decided to carry out a pilot study as well as to redo the Exploratory Factor Analysis (EFA) procedure on all the constructs in this study to determine the new combinations of measurement items as well as the Internal Reliability value on every construct and item chosen. For this purpose, the researcher has managed to gather data from 163 respondents in the pilot study that was carried out. This data will be used to undertake the Exploratory Factor Analysis (EFA) as well as other analyses required before the actual study or field study at a later time. The final findings of this study will determine a new model for this study.

\subsection{Problem Statement}

This study finds that many previous studies focused only on information sharing and there was a lack of studies regarding information sharing behavior using social media. Studies on social media usage 
was carried out on students, school teachers, buyers and public sector employees, but there has not been any study carried out on employees in government linked companies in Malaysia. The same is also true for the inventory to determine the level of employee behavior in accepting and using social media for official business in the organization. From the viewpoint of Human Resource Management (HRM), the researcher finds that organizations need to identify the behavior of employees in accepting and using social media before making information sharing using social media a requirement in the organization. No study has been found that identifies the factors that influence information sharing behavior using social media by including mediator and moderator factors to identify their relationship with information sharing behavior using social media. In addition, there is no set of instruments that studies intrinsic predictor factors, readiness for change as mediator factors and self-efficacy as moderator factors with information sharing behavior using social media, that can be validated and seen as credible to be adopted as an instrument to measure information sharing (Farajpour \& Yousefli, 2018) behavior using social media.

\section{Literature Review}

This study is based on the studies by Venkatesh et al. (2003) who worked on the usage of technology as well as factors that influenced the acceptance and usage of technology. The Unified Theory of the Acceptance and Use of Technology or known as UTAUT by Venkatesh et al. (2003) explains the relationship of the constructs namely performance expectancy, effort expectancy, social influence and facilities conditions as independent variables. Whereas intention is indicated as mediator factor. In UTAUT, the moderator factor is the demographic factors that consist of gender, age, experience and voluntariness to use. The dependent variable in this theory is use behavior. The UTAUT study is beginning to be widely used by later researchers by utilizing it on school students (Liu et al., 2014), in the banking industry (AbuShanab \& Pearson, 2007), also in the business sector (Agnihotri et al., 2012). In fact, the UTAUT study is also used for an inter-country comparison between the United State and China. Studies by Venkatesh et al. (2016) also support the use of selected variable factors, mediator factors and moderator in identifying its relationship with a new usage behavior. Studies by Lippke et al. (2009) also stressed the need for mediator and moderator usage in influencing certain physical activities (behavior). This study chooses to focus on information sharing behavior using social media by selecting constructs from previous studies found to be relevant to the study topic. By adapting and modifying reference models according to the suitability of the study, this study also borrows study survey items and modified it according to suitability of the field of study. Through the process of selecting variables and constructs, this study identifies intention, belief expectancy with a component of performance expectancy, effort expectancy and social influence as well as attitude influence with expected rewards, expected association and expected contribution as the independent variables for this study. For the mediator variable factor, this study identified readiness for change factor with components of organizational appropriateness, management support, change efficacy and personally beneficial. This study also identifies a moderator factor with the self-efficacy factor studied using the components of proficiency level and actual usage level.

\subsection{Information sharing behavior using social media}

Based on behavioral studies including previous theories and study models, the most outstanding theory for information sharing is the study by Davenport and Prusak (1998) that satisfies the requirements of this study as a dependent variable. Because this study studies employees' behavior, the Theory of Planned Behavior (TPB) by Ajzen (1991) and Theory of Reasoned Action (TRA) by Fishbein and Ajzen (1975) are blended perfectly for this study to identify the constructs and instruments. The TRA and TPB theories proposed factors that are related to the formation of human behavior based on intention, belief and attitude as constructs that greatly influence the formation of human behavior. Based on the TPB, TRA studies and the adaptation of information sharing study by Davenport and Prusak (1998), this study identifies the factor of information sharing using social media as a dependent variable with 
five items that have been modified and translated into Malay language. Although the same items are used, the sentences were modified with certain additions appropriate to this field of study. The following is an example of the original question, "I frequently participate in knowledge sharing activities." For this study, translation, addition and modification were done so that the question becomes "I frequently participate in knowledge sharing activities using social media." The items for this set of questionnaire have been widely used in previous studies, be it locally within the country or by researchers from abroad. This study has gathered questionnaires of previous researchers that are relevant to the requirements of this study and made it into a new instrument scale that is suitable to use when referring to the study of information sharing behavior using social media. This instrument is expecting to be used to measure information sharing behavior using social media for future researcher.

\subsection{Independent variable factors: Intention, belief expectancy and attitude influence}

The constructs of intention, belief expectancy and attitude influence were selected as the constructs to the study's independent variables. Because this study stresses on the issue of the usage of technology, then, apart from the TRA and TPB, other theories and models are also taken as main references. Both The Technology Acceptance Model (TAM) by Davis (1993) and UTAUT by Venkatesh et al. (2003) are the main references as this study involves the usage of technology. It is in line with the researcher's study that focuses on a more specific technology, namely, the use of social media. Four constructs in the UTAUT study and its instruments, namely, intention, performance expectancy, effort expectancy and attitude influence were selected, with fourteen items used as reference, adapted and modifies and used to form the instrument for measuring the independent variables of this study. Also used as a construct in this study is a construct from the TRA study i.e. attitude influence with the dimensions of expected rewards, expected association and expected contribution. Thirteen items in the questionnaire for this construct refers to the research instrument by Casimir et al. (2012). As with the items for dependent variables, the items in this questionnaire were changed and adapted according to the suitability for the field of study.

\subsection{Mediator factor: Readiness for change}

This study identifies the mediator factor that affects information sharing behavior using social media. The readiness for change factor by Holt et al., (2007) and the instrument adapted by Anjani (2013) were selected for this study. Lewin (1946) states that the development of the individual must go through change. There are three stages stated, the first, unfreezing; the second, the transformation of movement stage (changing); and the last stage is refreezing. This change process becomes an experience process and affects the behavior of the individual. Through this basis, Armenakis, Harris, \& Mossholder (1993) proposed a model to create readiness for change and proposed readiness for change as a precursor for behavior. Holt et al. (2007) then created an instrument to measure readiness for change. Anjani (2013) has used that instrument and the findings show that readiness for change has a significant relationship with the behavior of the organisation's employees. Therefore, this study wants to identify readiness for change as a construct that acts as a mediator factor towards the relationship of selected factors with information sharing behavior using social media. This survey uses all the constructs used by Anjani (2013), namely, appropriateness of the organization, management support, change efficacy and personally beneficial by adapting and translating twenty-five items in the readiness for change factor.

\subsection{Moderator factor: Self-efficacy}

According to Bandura (1977), self-efficacy is one of the important factors in determining the personality and behavior of the individual. Human behavior and the individual's work performance can be reflected by the self-efficacy factor. Bandura (2006) also identified that changes in human behavior are closely related to cognitive expectancy stimulation i.e. they expect that the event will happen or the effect from the experience of the event that is closely related to cognitive expectancy. Lippke et al. 
(2009) states that self-efficacy is a significant moderator factor and has a big impact on one's behavioral change expectancy. The self-efficacy construct proposed in studies by Teo et al. (1999) and Bock and Kim (2002) are regarding the proficiency level and actual usage level of social media software. For this questionnaire, for questions regarding proficiency, the researcher formulated them according to the requirements of the study and based on Web 2.0 social media technology as mentioned in the study by Bock and Kim (2002), whereas for the actual usage level, the questions were adapted from the research instrument by Teo et al. (1999). Five items in the questionnaire were about the level of usage of social media software and four questions were regarding the actual level of social media usage.

\section{Methodology/Materials}

The survey questions were adopt, adapted, and modified from the questions of previous studies. The questionnaire items were arranged according to chronological order of dependent variables, independent variables, mediator factors and moderator factors. There are sixty six items for the whole construct not inclusive of eleven questions on demographical factors. The original survey questions did not touch upon the usage of social media, therefore, items in this study added sentences for usage of social media or those with equivalent meaning. The questionnaire adapted into the information sharing behavior using social media instrument were originally in English and translated into Malay through back to back translations as suggested by Konting (1990) according to requirements and respondents' understanding, values and local culture. This study selects and adapts the instruments built by various earlier researchers in their respective fields of study as well as modifying a number of statements to be compatible with the field of study being carried out. According to Konting (1990), Steiger (1990), as well as Zainudin Awang (2015), if a researcher adapts the instruments built by previous researchers as well as modifies statements into new items, then they would have to re-do the Exploratory Factor Analysis (EFA) procedure. This is a need especially when the current field of study differs broadly from the previous field in which the instrument was built and validated. When the research respondent is different form the actual study, especially there are different in population, cultural, or lapse of time, it is a needs to re-do the EFA. The previous result may be differ and might not suit to the current environment. In line with that recommendation, the researcher has decided to carry out a Pilot Study first as well as to re-do the Exploratory Factor Analysis (EFA) on the items that measure each construct. This is important to determine the new combination of items that form a component as well as the Internal Reliability value of each component. For this purpose, the researcher randomly collected data from 163 respondents in the Pilot Study that was carried out. This data was used to carry out the Exploratory Factor Analysis (EFA) and other analyses required before the Field Study later. Validity and reliability analyses were carried out to ensure this survey has the stability to be used in Malaysia in general and specifically for organizations in Malaysia as well as future researchers.

\subsection{Exploratory Factor Analysis (EFA)}

Because this study proposes a new model, which comes from the adaptation of previous studies, the set of survey questions must undergo the EFA test in order to be suitable with the new study model. Failure to carry out validity and reliability testing may cause concern that the research instrument used will not be able to measure the study requirements and will not fulfill the study objectives, which wants to measure information sharing behavior using social media. The research instrument also needs to obtain validity from the experts in the field, namely, academics, research fields such as human resource management, statistics experts, language translation experts as well as Malay language experts when the translation process is carried out. When the validity and reliability of this instrument can be adopted after undergoing expert screening, pilot studies and the EFA process, only then this research instrument can be used in the actual study later. The findings of the actual study will determine the importance and answers to the question of information sharing behavior using social media among the employees of selected organizations. The researcher carried out the Exploratory Factor Analysis (EFA) for each construct separately and prepared a detailed report of the analysis findings so that there would be no more 
doubt or questions arising regarding the validity of the instrument used in the future field study. This procedure is imperative to determine the factor loading value for each item, the number of components extracted and the Internal Reliability value of each component that measures the construct. The purpose of this descriptive pilot study is to obtain content validity and the reliability value for the set of questionnaire. This study undergoes five stages including face-to-face meetings with field experts to review, assess and validate the usage of items and its suitability for each study construct. According to Konting (1990), six to nine experts are sufficient to assess the constructs and study items. The researcher met with six experts in their respective fields. The first stage was translation. The researcher met with a translation expert and a teacher who is the head of department for Bahasa Melayu. The second stage was item validity assessment by the field experts. The researcher met with three academicians and one HRM officer. The third stage was validity assessment by the employees in the field of study. The researcher met with seven employees of various ages, positions and departments. The fourth stage was gathering of information through a pilot study by distributing questionnaire forms to the respondents of the study. The fifth stage, all 163 sets of data were analyzed for reliability using the Exploratory Factor Analysis (EFA), using the SPPS AMOS software version 21.0.

\subsection{Validity and Reliability}

Many studies related to validity and reliability is carried out to ensure the instrument used is appropriate for the field of study. Surveys for the sharing of information were widely used in previous studies, among them studies by Hsu et al. (2007) that involves the study of information sharing behavior in a virtual community; Chen et al. (2009) who studied the increase in virtual learning to encourage information sharing in institutions of learning; Lin and Joe (2011) in their research on the management implications of organizational leaders to increase the ethical behavior of employees with regards to information sharing; and Tseng and Huang (2011) who carried out research on the usage of Wikipedia and Web 2.0 software and its relationship to employees' performance. Nunnally and Bernstein (1994) discussed the need to use more than one item to measure a psychological parameter. Since behavior is a psychological trait, therefore, the researcher selected at least three items for one measurement instrument of each construct and study component. Table 1 shows the general coefficient determining the item reliability for use with the research instrument. The items selected in this study are based on items in previous studies that exceeded that minimum reliability value to measure the study construct of at least $\alpha>0.7$.

\subsection{Location and subject of study}

The location and study for the first phase was a face-to-face meeting with a translator from the Malaysian Institute of Translation \& Books (ITBM), also a Bahasa Melayu teacher from Sekolah Jalan 3, Bangi, Selangor. Face-to-face meetings were also held with an academician, a language expert and an academician in the field of statistics at Universiti Pertahanan Nasional Malaysia (UPNM). Face-to-face meetings were also held with experts in instruments and statistics at Universiti Sultan Zainal Abidin (UnisZA), Kuala Lumpur branch campus. Face-to-face meetings were also held with two expert academicians in the human resource management field in Universiti Putra Malaysia, Serdang, Selangor and a human resource officer from a government department. The third stage was held at the offices of one government-link company (GLC) with seven employee representatives from all levels, ages and departments to assess the usage of language, understanding, clarity and suitability of the choice of questions from the employees' viewpoint. Three of them were practitioners in the field that is, related to human resource management (HRM). The fourth stage took place at Bangunan Lembaga Tabung Angkatan Tentera, Jalan Bukit Bintang, Kuala Lumpur, Malaysia, at the human resource management office for the purpose of the distribution of the questionnaires. The researcher made an appointment with a HRM officer of the Armed Forces Fund Board (LTAT). After the agreed period of time had elapsed, the researcher met again with the HRM officer and retrieved the questionnaires that had been completed. The fifth phase as uploading the survey data into the SPSS software. This process was done 
by the researcher and the study findings checked and improved by a statistics expert, a trainee and also a lecturer who wrote a book about Structural Equation Modeling. The subjects of the pilot study were the employees at the Armed Forces Fund Board (LTAT), a government-link investment company (GLIC). 163 respondents completed questionnaire forms $(n=163)$ for this EFA test. All the respondents of this pilot study are employees who fulfill the criteria for the field of study.

\subsection{Research instrument}

The research instrument used is a survey instrument was prepared in dual languages. All the scales were adapted from prior research and rephrased to suit the information sharing behavior using social media's context. The researcher selected, borrowed and retained the questions in English with the improvements as accepted at the stage of instrument selection, also those adapted according to the suitability of the field of study by adding the Malay translations under each English language question item. Sixty-six (66) study items were made into one set of research instrument to measure information sharing behavior using social media. For the measurement scale of the study items, the researcher followed a suggestion by the instrument expert, using 10 scales $^{31}$. The measurement of items for Parts B, C and $\mathrm{D}$ begin at the scale of 1 (strongly disagree) until 10 (strongly agree), whereas for Part $\mathrm{E}$, for question QE1, using the scale of 1 (not at all confident) until 10 (very confident) and for QE2 using the scale of 1 (very rarely) until 10 (very frequent).

\section{Results and Findings}

The research instrument set was given to all employees of LTAT as respondents for the pilot study. There are 262 employees at LTAT and within two weeks, the LTAT HRM representative collected and returned 178 forms, however, only 163 were filled up completely. Using the SPSS AMOS version 2.1, the findings of the pilot study were reported according to the constructs of the study's variables. The Exploratory Factor Analysis (EFA) procedure using the Principal Component Analysis (PCA) with Varimax Rotation was carried out in the items in the study's constructs. The study also reported the value of Total Variance Explained (TVE). This is important for the researcher to report how far the item that was used can contribute towards measuring a certain construct of study. Meanwhile, the Measure of Sampling Adequacy by Kaiser-Meyer-Olkin (KMO) must exceed the required minimum value of 0.6. This finding also reports on the Factor Loading (FL) for each item to ensure these items exceed the minimum limit set in order to be appropriate for use as a research instrument. Information that needs to be reported is the Internal Reliability value.

\subsection{Proposed Inventory Information Sharing Behavior}

Those items measuring the construct were performed by using the Exploratory factor analysis (EFA) using the extraction method of Principal Component with Varimax (Variation Maximization) rotation. The results shows that Bartlett's Test and KMO for Information Sharing Behavior (ISB) .000 and .871; Intention (IN) .000 and .782; Belief Expectancy (BE) .000 and .911; Attitude Influence (AI) .000 and .925; Readiness for Change (RFC) .000 and .959; and Self-Efficacy (SE) .000 and .902. Table 1 indicates the results of Bartletts' Test of Sphericity and Kaiser-Meyer-Olkin (KMO). Bartletts' Test of Sphericity results for all items is significant with P-Value $<0.05$ while Kaiser-Meyer-Olkin (KMO) results show that all items that is exceeded the required value which is more than 0.6 . With this result, the data is adequate, can proceed with the next step, and can be used in actual research.

\subsection{Reliability coefficient}

In measuring the latent construct, this study needs to compute the value of Cronbach's Alpha to determine the Internal Reliability of the retained items. This internal reliability indicates how strong the respective items are holding to each other in measuring the same construct. 
Table 1

Descriptive Statistic (Mean and Standard Deviation)

\begin{tabular}{|c|c|c|c|c|c|}
\hline Construct's Item & Mean & Sphericity & $\mathrm{KMO}$ & TVE & FL \\
\hline Information Sharing Behavior & & .000 & .871 & .74 .774 & \\
\hline Item ISB1 & 5.73 & & & & .848 \\
\hline Item ISB2 & 5.33 & & & & .910 \\
\hline Item ISB3 & 5.49 & & & & .904 \\
\hline Item ISB4 & 5.09 & & & & .819 \\
\hline Item ISB5 & 5.42 & & & & .838 \\
\hline Intention (IN) & & .000 & .782 & 93.267 & \\
\hline Item IN1 & 5.85 & & & & .963 \\
\hline Item IN2 & 5.94 & & & & .968 \\
\hline Item IN3 & 6.07 & & & & .966 \\
\hline Belief Expectancy (BE) & & .000 & .911 & & \\
\hline Performance Expectancy (PE) & & & & 38.275 & \\
\hline Item PE1 & 6.18 & & & & .809 \\
\hline Item PE2 & 6.15 & & & & .880 \\
\hline Item PE3 & 6.12 & & & & .891 \\
\hline Item PE4 & 6.50 & & & & .845 \\
\hline Effort Expectancy (EE) & & & & 65.074 & \\
\hline Item EE1 & 6.35 & & & & .779 \\
\hline Item EE2 & 6.47 & & & & .900 \\
\hline Item EE3 & 6.58 & & & & .887 \\
\hline Item EE4 & 6.54 & & & & .816 \\
\hline Social Influence (SI) & & & & 85.589 & \\
\hline Item SI1 & 5.42 & & & & .730 \\
\hline Item SI2 & 6.99 & & & & .732 \\
\hline Item SI3 & 6.34 & & & & .753 \\
\hline Attitude Influence (AI) & & .000 & .925 & & \\
\hline Expectation Reward (ER) & & & & 61.562 & \\
\hline Item ER1 & 5.12 & & & & .895 \\
\hline Item ER2 & 5.13 & & & & .916 \\
\hline Item ER3 & 5.17 & & & & .856 \\
\hline Expectation Association (EA) & & & & 82.946 & \\
\hline Item EA1 & 6.15 & & & & .935 \\
\hline Item EA2 & 6.25 & & & & .937 \\
\hline Item EA3 & 6.24 & & & & .938 \\
\hline Item EA4 & 6.20 & & & & .933 \\
\hline Item EA5 & 6.20 & & & & .917 \\
\hline Expectation Contribution (EC) & & & & 89.470 & \\
\hline Item EC1 & 6.29 & & & & .879 \\
\hline Item $\mathrm{EC} 2$ & 6.33 & & & & .889 \\
\hline Item EC3 & 6.36 & & & & .817 \\
\hline Item EC4 & 6.33 & & & & .828 \\
\hline Item EC5 & 6.39 & & & & .797 \\
\hline Readiness for Change (RFC) & & .000 & .959 & & \\
\hline Organizational Appropriateness (OA) & & & & 34.278 & \\
\hline Item OAl & 6.61 & & & & .694 \\
\hline Item $\mathrm{OA} 2$ & 6.61 & & & & .790 \\
\hline Item $\mathrm{OA} 3$ & 6.55 & & & & .807 \\
\hline Item OA4 & 6.59 & & & & .805 \\
\hline Item OA5 & 6.59 & & & & .813 \\
\hline Item OA6 & 6.58 & & & & .796 \\
\hline Item $\mathrm{OA} 7$ & 6.59 & & & & .808 \\
\hline Item OA8 & 6.60 & & & & .789 \\
\hline Item OA9 & 6.59 & & & & .796 \\
\hline Item OA10 & 6.47 & & & & .760 \\
\hline Management Support (MS) & & & & 64.354 & \\
\hline Item MS1 & 6.15 & & & & .792 \\
\hline Item MS2 & 6.00 & & & & .853 \\
\hline Item MS3 & 5.94 & & & & .849 \\
\hline Item MS4 & 5.90 & & & & .865 \\
\hline Item MS5 & 5.88 & & & & .702 \\
\hline Item MS6 & 5.74 & & & & .769 \\
\hline Change Efficacy (CE) & & & & 89.107 & \\
\hline Item CE1 & 6.42 & & & & .753 \\
\hline Item CE2 & 6.42 & & & & .777 \\
\hline Item CE3 & 6.43 & & & & .777 \\
\hline Item CE4 & 6.34 & & & & .805 \\
\hline Item CE5 & 6.39 & & & & .807 \\
\hline Item CE6 & 6.44 & & & & .793 \\
\hline Personal Benefit (PB) & & & & 91.009 & \\
\hline Item PB1 & 6.57 & & & & .778 \\
\hline Item PB2 & 6.56 & & & & .673 \\
\hline Item PB3 & 6.43 & & & & .632 \\
\hline Self-Efficacy (SE) & & .000 & .902 & & \\
\hline Level of proficiency (LoP) & & & & 53.116 & \\
\hline Item LoP1 & 5.14 & & & & .859 \\
\hline Item LoP2 & 5.80 & & & & .853 \\
\hline Item LoP3 & 6.36 & & & & .698 \\
\hline Item LoP4 & 6.64 & & & & .671 \\
\hline Item LoP5 & 7.18 & & & & .757 \\
\hline Level of actual use (LAU) & & & & 81.442 & \\
\hline Item LAU1 & 6.36 & & & & .921 \\
\hline Item LAU2 & 6.35 & & & & .932 \\
\hline Item LAU3 & 6.29 & & & & .924 \\
\hline Item LAU4 & 6.42 & & & & .912 \\
\hline
\end{tabular}


By using the Alpha Cronbach value, it is measuring the instrument's reliability. The Alpha Cronbach Value $(\alpha)$ of each construct must exceed the reliability minimum limit of 0.7 for the items to achieve the Internal Reliability. Only when every items have achieved the minimum requirement, those items can be adopted and used for future research. Table 2 shows each item in the pilot study for the reliability coefficient. The results show that every item is exceeded the limit of $\alpha>0.7$, therefore the items in this study's questionnaire can be used to measure the constructs of this study. Next, this study, with the acceptance of validity and reliability of the research instrument, has proposed a research conceptual framework.

\section{Table 2}

Reliability coefficient result using Cronbach Alpha

\begin{tabular}{lcc}
\hline Component & Number of Item & Cronbach Alpha $(\alpha)$ \\
\hline Information sharing behavior using social media & 5 & 0.915 \\
Intention & 3 & 0.963 \\
Performance Expectancy & 4 & 0.970 \\
Effort Expectancy & 4 & 0.920 \\
Social Influence & 3 & 0.782 \\
Expectation Reward & 5 & 0.978 \\
Expectation Association & 3 & 0.888 \\
Expectation Contribution & 5 & 0.968 \\
Organizational Appropriateness & 10 & 0.988 \\
Management Support & 6 & 0.968 \\
Change Efficacy & 6 & 0.980 \\
Personal Benefit & 3 & 0.956 \\
Level of proficiency & 5 & 0.870 \\
Level of actual use & 6 & 0.978 \\
\hline
\end{tabular}

\subsection{Proposed Model of Information Sharing Behavior Using Social Media}

This study also proposes the new integrate model of information sharing behavior. Fig. 1 shows the propose of the new integrate model of information sharing behavior using social media (MISB-USM). The finding of the actual study in the future will further strengthen the theory and model of this study.

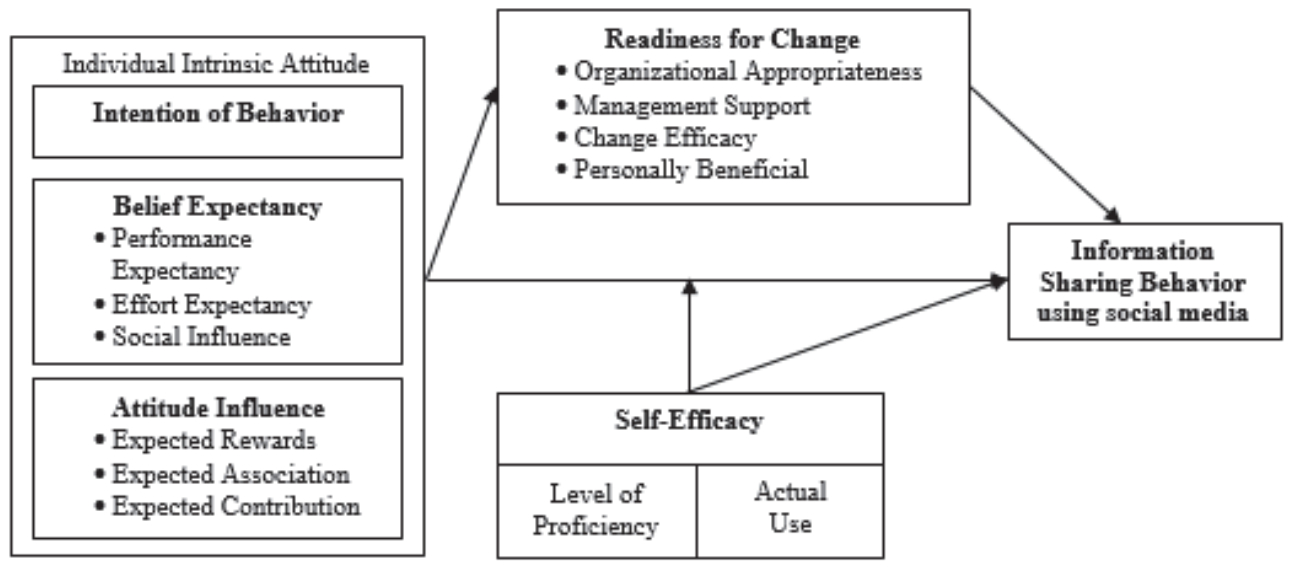

Fig. 1. New Integrate Model of Information Sharing Behavior Using Social Media

\section{Conclusion}

Exploratory Factor Analysis (EFA) shows that all latent constructs in the model measured using certain components. The items in all component that measure the latent constructs have good internal reliability with a Cronbach's Alpha values exceeding the required degree of 0.7. Hence, the researcher will rearrange the items by the same component category and continue collecting data for actual research later. The field data obtained will be used in Confirmatory Factor Analysis (CFA) and Structural Equation 
Modeling (SEM) procedure. This study has succeeded in building a research model based on previous research models and theories related to behavior, information sharing and the use of technology. This study also succeeded in gathering items from research constructs and formed a set of survey questions as an instrument to measure information sharing behavior using social media. This instrument passed the validity and reliability tests for all items and is appropriate for use in future research related to information sharing behavior using social media. This study directly supports the main research theory, namely the Unified Theory of Acceptance and Use of Technology (Venkatesh et. al., 2003) as well as the theory of readiness for change by Holt et al., (2007) and the theory of self-efficacy by Bandura (1993) that the behavior of individuals require predictor, mediator and moderator factors to motivate the individual to do or undertake any change. As stated by Lewin (1946), change needs to happen by unfreezing the old behavior and ready for transformation by adapting what is currently needed, and then refreezing the new behavior that is appropriate to the required change. The research instrument is ready to be used in actual field studies and by other researchers undertaking studies in the same field; in fact, it can also be used by the practitioners of human resource management. Future researchers can directly carry out their studies using the Model of Information Sharing Behavior Using Social Media (MISB-USM) among the employees of an organization.

\subsection{The implication of the study}

The implications of this study focus on the theoretical and practical aspects of human resource management. Theoretically, this study supports the previous theories and research models especially UTAUT, TRA, TPB theories in the relationship with individual behavior variables. This study also provides input that the theories used such as the change theory by Lewin (1946) is still relevant especially in studies involving behavior, even on new dependent variable subjects. Practically, this study provides the opportunity for future researchers to use this inventory as a measurement instrument in actual research and validates that MISB-USM can be accepted as a model for research that involves behavior, especially in human resource management. The implications of this study are also practical in human resource management, where organizations that wish to assess the employees' intrinsic factor level as well as the effect of the mediator factor, which is readiness for change and the moderator factor, which is self-efficacy, upon information sharing behavior using social media among the organization's members, can refer to the findings of the questionnaire among employees by using the IISB-USM. Gathering the whole set of item intone set of questionnaire with the positive result from EFA, makes this research has come out with its new inventory called Inventory Information Sharing Behavior Using Social Media (IISB-USM) and is suggested to be used in an actual study.

\subsection{Propose for the future research}

Based on the study findings, the researcher is suggesting that future studies use this instrument as an inventory questionnaire on the employees of organizations in Malaysia especially among the Government-Link Company (GLC). The researcher also suggests the future research to fully utilize the Structural Equation Modelling (SEM) methodology. The research findings using SEM can create a Structural Model where this finding becomes more valid for the Model of Information Sharing Behavior Using Social Media (MISB-USM) to be accepted and used in the field of social sciences, generally and human resource management, specifically.

\section{References}

AbuShanab, E., \& Pearson, J. M. (2007). Internet banking in Jordan: The unified theory of acceptance and use of technology (UTAUT) perspective. Journal of Systems and information Technology, 9(1), 78-97.

Agnihotri, R., Kothandaraman, P., Kashyap, R., \& Singh, R. (2012). Bringing “social” into sales: The 
impact of salespeople's social media use on service behaviors and value creation. Journal of Personal Selling \& Sales Management, 32(3), 333-348.

Ajzen, I. (1991). The theory of planned behavior. Organization Behaviour and Human Decision Process, 50, 179-211.

Anjani, P. K. (2013). Impact of Readiness for Change on Organizational Change of Banking Sector in Salem District. International Journal of Management and Business Research, 3(4), 353-371.

Armenakis, A. A., \& Bedeian, A. G. (1999). Organizational change: A review of theory and research in the 1990s. Journal of Management, 25(3), 293-315.

Armenakis, A. A., Harris, S. G., \& Mossholder, K. W. (1993). Creating readiness for organizational change. Human relations, 46(6), 681-703.

Awang, Z. (2015). SEM Made Simple: A Gentle Approach to Learning Structural Equation Modeling. Selangor, Malaysia: MPWS Rich Publication Sdn. Bhd.

Bandura, A. (1977). Self-efficacy: toward a unifying theory of behavioral change. Psychological Review, 84(2), 191-215.

Bandura, A. (1993). Perceived self-efficacy in cognitive development and functioning. Educational psychologist, 28(2), 117-148.

Bandura, A. (2006). Guide for constructing self-efficacy scales. Self-efficacy beliefs of adolescents, 5(1), 307-337.

Bock, G. W., \& Kim, Y. G. (2001). Breaking the myths of rewards: An exploratory study of attitudes about knowledge sharing. Information Resouroce Managamant Journal, 15(2), 14-21.

Casimir, G., Ngee Keith Ng, Y., \& Liou Paul Cheng, C. (2012). Using IT to share knowledge and the TRA. Journal of Knowledge Management, 16(3), 461-479.

Chen, I. Y., \& Chen, N. S. (2009). Examining the factors influencing participants' knowledge sharing behavior in virtual learning communities. Journal of Educational Technology \& Society, 12(1), 134.

Davenport, T. H., \& Prusak, L. (1998). Working knowledge: How organizations manage what they know. Harvard Business Press.

Davis, F. D. (1993). User acceptance of information technology: system characteristics, user perceptions and behavioral impacts. International Journal of Man-machine Studies, 38(3), 475-487.

Farajpour, F \& Yousefli, A. (2018). Information flow in supply chain: A fuzzy TOPSIS parameters ranking.Uncertain Supply Chain Management, 6(2), 181-194.

Fishbein, M., \& Ajzen, I. (1975). Belief, attitude, intention and behavior: An introduction to theory and research.

Lewin, K. (1946). Action research and minority problems. Journal of Society Issues, 2, 34-46.

Holt, D.T., Armenakis, A.A., Harris, S.G., \& Field, H.S.(2007). Toward a comprehensive definition of readiness for change: A review of research and instrumentation. Research in Organizational Change and Development, 16(6), 289-336.

Liu, C. C., Lin, C. C., Deng, K. Y., Wu, Y. T., \& Tsai, C. C. (2014). Online knowledge sharing experience with creative commons. Online Information Review, 38(5), 680-696.

Lippke, S., Wiedemann, A. U., Ziegelmann, J. P., Reuter, T., \& Schwarzer, R. (2009). Self-efficacy moderates the mediation of intentions into behavior via plans. American Journal of Health Behavior, 33(5), 521-529.

Lippke, S., Wiedemann, A. U., Ziegelmann, J. P., Reuter, T., \& Schwarzer, R. (2009). Self-efficacy moderates the mediation of intentions into behavior via plans. American Journal of Health Behavior, 33(5), 521-529.

Konting, M.M. (1990). Kaedah Penyelidikan Pendidikan. Kuala Lumpur: Dewan Bahasa dan Pustaka; 1990.

Hair, J. F., Black, W. C., Babin, B. J., Anderson, R. E., \& Tatham, R. L. (2006). Multivariate data analysis. Upper Saddle River, NJ: Prentice hall.

Holt, D. T., Bartczak, S. E., Clark, S. W., \& Trent, M. R. (2007). The development of an instrument to measure readiness for knowledge management. Knowledge Management Research \& Practice, 5(2), 75-92.

Hsu, M. H., Ju, T. L., Yen, C. H., \& Chang, C. M. (2007). Knowledge sharing behavior in virtual 
communities: The relationship between trust, self-efficacy, and outcome expectations. International Journal of Human-Computer Studies, 65(2), 153-169.

Lin, C. P., \& Joe, S. W. (2012). To share or not to share: Assessing knowledge sharing, interemployee helping, and their antecedents among online knowledge workers. Journal of Business Ethics, 108(4), 439-449.

Nunnally, J.C., \& Bernstein, I.H. (1994). Psychometric Theory. 3rd ed. New York: McGraw-Hill.

O'Reilly, T., \& Battelle, J. (2009). Web squared: Web 2.0 five years on. " O'Reilly Media, Inc.".

Osburn, H. G. (2000). Coefficient alpha and related internal consistency reliability coefficients. Psychological methods, 5(3), 343.

Ryan, R. M., \& Deci, E. L. (2000). Self-determination theory and the facilitation of intrinsic motivation, social development, and well-being. American Psychologist, 55(1), 68.

Singh, H., Garg, R \& Sachdeva, A. (2018). Investigating the interactions among benefits of information sharing in manufacturing supply chain.Uncertain Supply Chain Management, 6(3), 255-270.

Steiger, J. H. (1990). Structural model evaluation and modification: An interval estimation approach. Multivariate Behavioral Research, 25(2), 173-180.

Teo, T. S., Lim, V. K., \& Lai, R. Y. (1999). Intrinsic and extrinsic motivation in Internet usage. Omega, 27(1), 25-37.

Tseng, S. M., \& Huang, J. S. (2011). The correlation between Wikipedia and knowledge sharing on job performance. Expert Systems with Applications, 38(5), 6118-6124.

Venkatesh, V., Morris, M. G., Davis, G. B., \& Davis, F. D. (2003). User acceptance of information technology: Toward a unified view. MIS quarterly, 27(3), 425-478.

Venkatesh, V., \& Zhang, X. (2010). Unified theory of acceptance and use of technology: US vs. China. Journal of Global Information Technology Management, 13(1), 5-27.

Venkatesh, V., Thong, J. Y., \& Xu, X. (2016). Unified theory of acceptance and use of technology: A synthesis and the road ahead. Journal of Association of Information Systems, 17(5), 328-376.

Vroom, VH. (1964). Work and Motivation. New York: Wiley.

Yousafzai, S. Y., Foxall, G. R., \& Pallister, J. G. (2010). Explaining internet banking behavior: Theory of reasoned action, theory of planned behavior, or technology acceptance model?. Journal of Applied Social Psychology, 40(5), 1172-1202.

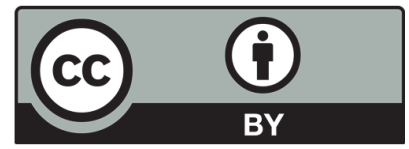

(C) 2018 by the authors; licensee Growing Science, Canada. This is an open access article distributed under the terms and conditions of the Creative Commons Attribution (CC-BY) license (http://creativecommons.org/licenses/by/4.0/). 